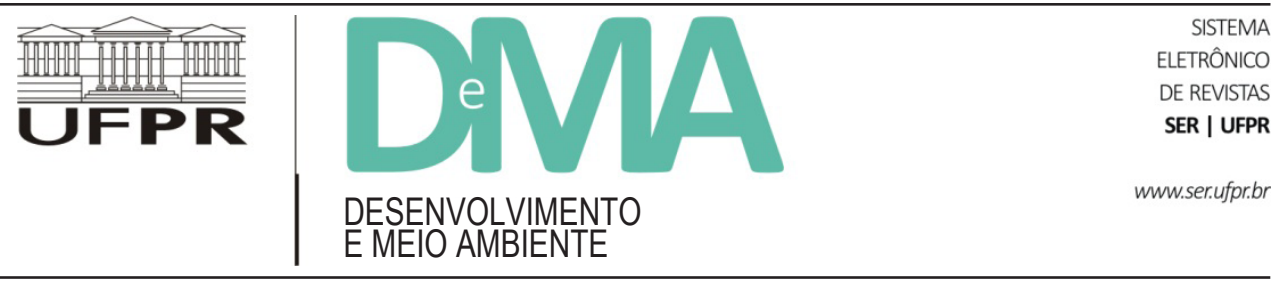

\title{
Construção política das imagens e das representações: os girassóis do Tocantins (Brasil)
}

\section{Building the Policy on Images and Representations: The Sunflowers of Tocantins (Brazil)}

\author{
Kelly BESSA ${ }^{1 *}$, Liliane Flávia Guimarães da SILVA², Walena Almeida MARÇAL ${ }^{2}$, Fábio Henrique de Melo \\ RIBEIRO $^{1}$, Eva Barros MIRANDA ${ }^{1}$, Talita Butarello MUCARI ${ }^{1}$ \\ ${ }^{1}$ Universidade Federal do Tocantins (UFT), Palmas, TO, Brasil. \\ ${ }^{2}$ Instituto Federal de Educação, Ciência e Tecnologia do Tocantins (IFTO), Palmas, TO, Brasil. \\ *E-mail de contato: kellybessa@uft.edu.br
}

Artigo recebido em 18 de fevereiro de 2016, versão final aceita em 14 de março de 2017.

RESUMO: Considerando as projeções simbólicas forjadas pelo poder público e pelos grupos sociais dominantes, o presente artigo objetiva compreender as relações político-identitárias engendradas no movimento de construção de símbolos próprios para o Tocantins, que passam a ser assimilados e apropriados pela esfera social. Entre esses símbolos, destaca-se, de modo emblemático, o girassol, que, por meio da ação do poder político estadual, encontra-se entre os símbolos oficiais da natureza do Tocantins, transformado em tradição para o devir, sobretudo pelos esforços de projeção de memória de um passado recente.

Palavras-chave: projeções simbólicas; girassóis do Tocantins; relações político-identitárias.

ABSTRACT: Considering the symbolic representations shaped by the public power and by prevalent social groups, the present article has the objective of understanding the political-identity relationships engendered through the construction movement of symbols of the state of Tocantins, as they are assimilated and assumed by the social sphere. Among those symbols, the sunflower is singular and distinctive; the state political influence has helped making it prominent among the official symbols of the nature of Tocantins. It has been transformed into a tradition for the future generations, especially because of the efforts of projecting memories of a recent past.

Keywords: symbolic images; sunflowers of Tocantins; collective political identity. 


\section{Introdução}

O presente artigo, considerando as projeções simbólicas forjadas pelo poder público e pelos grupos sociais dominantes, objetiva compreender as relações político-identitárias engendradas no movimento de construção de símbolos próprios para o Tocantins, que passam a ser assimilados e apropriados pela esfera social. Entre esses símbolos, destaca-se, de modo emblemático, o girassol, que se encontra entre os símbolos oficiais da natureza do Tocantins (Tocantins, 2012).

O girassol foi institucionalizado como símbolo da natureza do Tocantins por força de lei (Tocantins, 2012), apesar de não ser uma planta dos biomas presentes no estado. Além dessa institucionalização, o poder público, por meio de seus agentes políticos, notoriamente nos governos de José Wilson Siqueira Campos $^{1}$ e de seu filho, Eduardo Siqueira Campos ${ }^{2}$, reforça sua veiculação e propagação, inserindo o nome e a imagem do girassol em espaços e edifícios públicos, documentos institucionais, insígnias, propagandas etc. (Tocantins, 2011). Some-se a essas iniciativas oficiais o cultivo da planta em espaços públicos na capital, Palmas, especialmente na Praça dos Girassóis, sede do poder estadual. ${ }^{3}$

O nome e a imagem do girassol também vêm sendo apropriados por instituições e empresas privadas, sobretudo em Palmas, demonstrando que o símbolo ganha expressão em outras esferas que transcendem a do poder e que, mesmo sendo forjado, tramado, ganha aderência na esfera social, que passa a assimilar e a comungar com os símbolos impostos.
Para tanto, partiu-se de uma pesquisa documental, que se concentrou na consulta aos registros impressos dos veículos de comunicação e a documentos oficiais do Estado, sendo realizada na Secretaria de Comunicação do Estado do Tocantins (SECOM), no acervo do Museu do Palacinho, no Instituto Siqueira Campos, no acervo do Jornal do Tocantins e na legislação estadual. Também foi realizada entrevista dirigida, com questões abertas, com o principal agente envolvido na criação desse símbolo - o ex-governador José Wilson Siqueira Campos (Siqueira Campos, 2014). Para analisar a assimilação e a apropriação do girassol como símbolo na esfera social em Palmas, foi realizado levantamento das instituições e empresas privadas que levam o termo girassol em seu nome fantasia, nas seguintes fontes: catálogo telefônico, sítios de busca da rede mundial de computadores (Internet), Junta Comercial do Estado do Tocantins (JUCETINS) e na Delegacia da Receita Federal.

\section{O "vazio" identitário e a projeção de símbolos oficiais forjados pelo Estado do Tocantins}

O Tocantins é o mais novo estado da federação brasileira, criado por meio da Assembleia Nacional Constituinte, em outubro de 1988, com o desmembramento e a emancipação política da porção norte do Estado de Goiás (Brasil, 1988) e instalado, na Região Norte, em $1^{\circ}$ de janeiro de 1989.

Para sediar o aparato político-administrativo, foi projetada uma nova cidade - Palmas, hoje,

\footnotetext{
${ }^{1}$ Os mandatos de José Wilson Siqueira Campos foram nos seguintes períodos: 1989 a 1991; 1995 a $1998 ; 1999$ a $2002 ; 2011$ a 2014.

2 Refere-se ao mandato de Eduardo Siqueira Campos como prefeito da capital do Tocantins, de 1993 a 1997.

${ }^{3}$ Nos períodos em que esses políticos não estavam no poder, especialmente no Poder Executivo (governo estadual e Prefeitura de Palmas), vale ressaltar que ocorreram tentativas de desconstrução do girassol como símbolo do Estado do Tocantins e de sua capital, Palmas. A respeito dos processos de construção, destruição e reconstrução de símbolos político identitários no Tocantins, ver Costa dos Anjos (2015).
} 
capital do Tocantins, inaugurada em 20 de maio de 1989 , momento do lançamento da pedra fundamental. Em $1^{\circ}$ de janeiro de 1990, foram instalados os governos estadual e municipal em Palmas, que, desse momento em diante, assumiu posição como centro do poder político, antevendo as perspectivas como centro do poder econômico e identitário no novo estado.

A partir da criação do estado, de sua instalação na Região Norte e da projeção de sua capital estadual, novos sentidos simbólicos foram instaurados com relação às identidades e às representações territoriais. Até 1988, o território que, hoje, compõe o Tocantins pertencia ao antigo norte de Goiás e à Região Centro-Oeste, tendo como capital política a cidade de Goiânia. Como aponta Rodrigues (2011, p. 26), "[...] as referências culturais e sociais [...] eram goianas e as pessoas se reconheciam enquanto tal”. Porém, diante da emancipação política, “[...] as identidades e as experiências ganharam novos contornos [...]", pois, "[...] da noite para o dia, de 31 de dezembro de 1988 para o dia $1^{\circ}$ de janeiro de 1989, todos amanheceram tocantinenses [...]", mas sem um passado que os identificasse como tocantinenses, sem um conjunto de símbolos que os representasse como pertencentes ao Tocantins e não ao antigo norte goiano.

Diante da "perda" das identidades territoriais e do consequente "vazio" identitário instaurado, suscitou-se a necessidade de construção de novos sentidos simbólicos para as identidades e as representações socioterritoriais. Para sanar tal problema, o novo estado, pela ação de governantes vinculados à própria luta emancipatória, com destaque para Siqueira Campos, primeiro governador, vem construindo um conjunto de projeções simbólicas forjadas. Tais projeções influenciam as representações sociais e os significados da identidade do "ser tocantinense" e do "ser palmense". Como sugere
Rodrigues (2011, p. 26), "as identidades territoriais foram, aos poucos, inventadas para produzir uma noção de pertencimento ao estado tocantinense".

Em Palmas, é marcante a existência de monumentos, edificações, memoriais e espaços criados pelo poder público, estadual e municipal, para forjar as identidades tocantinense e palmense, expressando a natureza política das formas simbólicas, sobretudo no espaço urbano (Boyer, 1994; Corrêa, 2013). Segundo Silva (2008), a Praça dos Girassóis, no centro cívico da cidade, demonstra isso de forma clara, com vários monumentos, entendidos como formas simbólicas eminentemente tocantinenses, que, no entanto, parecem não ter conexão entre si, como se fossem quadros soltos de uma história tramada.

Com relação aos símbolos e imagens, boa parte desses é legitimada por meio de leis e decretos estaduais, como é o caso dos símbolos oficiais (o brasão das armas, a bandeira, o hino e o selo estaduais) (Tocantins, 1989a) e dos símbolos da natureza do Tocantins (o girassol, a fava-de-bolota, a arara-canindé, a rolinha-fogo-apagou e a granada) (Tocantins, 2012).Tal fato demonstra que a "[...] invenção de tradições é essencialmente um processo de formalização e ritualização [...]" (Hobsbawm \& Ranger, 2008, p. 11), já que as imagens e os símbolos ganham expressão no âmbito do poder.

Nas palavras de Oliveira (2012, p. 276), instituiu-se "[...] uma política de construção de uma nova identidade cultural, econômica e política, construindo alegorias, disseminando fatos e mitos pouco representativos à história da então região norte de Goiás". Tais relações de poder forjaram, por meio de atos e discursos políticos, "um imaginário coletivo em torno do espaço de representação tocantinense, manipulando, inclusive, a formação de uma identidade cultural regional" (Rodrigues, 2010, p. 3). A identidade territorial, no Tocantins, foi 
sendo forjada por símbolos, imagens, fatos e mitos, utilizando-se de uma condição essencial à natureza humana, o caráter simbólico (Sola-Morales, 2014).

Esses símbolos forjados e oficialmente legitimados vêm construindo as tradições inventadas do Tocantins, ratificando o papel desses símbolos urdidos, tornando-os disponíveis e acessíveis para a sociedade, que, por sua vez, vem assimilando e comungando com tais símbolos impostos.

\subsection{Os símbolos oficiais do Estado e da natureza do Tocantins}

Nos primeiros anos de criação do Tocantins, foram forjadas projeções simbólicas oficiais, na tentativa de delinear a identidade tocantinense, diferenciada da identidade goiana. Tais ações contribuíram para fortalecer o poder instaurado, assim como a manutenção do status quo constituído.

Os símbolos oficiais do Tocantins foram instituídos no primeiro mandato de Siqueira Campos (1989 a 1991) como governador, por meio da Constituição Estadual, de 5 de outubro de 1989 (Tocantins, 1989a). No art. $3^{\circ}$ dessa Constituição, determinam-se, como símbolos oficiais do Tocantins, o brasão das armas, a bandeira, o hino e o selo estaduais (Tocantins, 1989a).

No transcurso do tempo, apenas o brasão e a bandeira foram mantidos como símbolos oficiais por meio de leis específicas (Tocantins, 1989b; 1989c). O hino do Tocantins, de autoria de Liberato Costa Póvoa e música de Abiezer Alves da Rocha (Tocantins, 1998), foi novamente homologado como símbolo oficial do estado no segundo mandato de Siqueira Campos (1995 a 1998), apesar das controvérsias. As referências históricas contidas na letra, especialmente a frase "[...] de Teotônio Segurado a Siqueira Campos [...]” (Tocantins, 1998, s/p.), que estabelece conexões entre o passado e o presente, de modo a perpetuar-se na memória simbólica, têm sido pauta de debates, tanto na Assembleia Legislativa como no Poder Executivo, sobretudo em governos de oposição ao ex-governador Siqueira Campos.

Não obstante, em 2013, Siqueira Campos, em seu quarto mandato como governador (2011 a 2014), instituiu uma comissão para deliberar sobre a conveniência e oportunidade de serem adotadas letra e música novas para o hino do Tocantins, por meio do Ato n. 1.063, de 6 de junho de 2013, publicado no diário oficial do estado (Tocantins, 2013a). A proposta consistiria em analisar a pertinência de se adotar como hino oficial a canção "Hino ao Tocantins", atual canção-símbolo do estado, de letra e música de autorias de Genésio Tocantins Sampaio Filho (Tocantins, 2002). Nessa canção, a letra não traz referências explícitas aos movimentos separatistas para a criação do estado e tampouco destaca personagens como Teotônio Segurado ou Siqueira Campos, mas fala do povo, da flora, da fauna e dos minerais tocantinenses, que, de maneira mais óbvia, são pertencentes à coletividade tocantinense (Tocantins, 2002).

Há também os símbolos oficiais da natureza do Estado do Tocantins, que foram instituídos pela Lei Estadual n. 915, de 16 de julho de 1997 (Tocantins, 1997), no segundo mandato de Siqueira Campos como governador (1995 a 1998). Essa lei foi, recentemente, substituída pela Lei Estadual n. 2.619, de 9 de agosto de 2012 (Tocantins, 2012), promulgada no quarto mandato de Siqueira Campos (2011 a 2014), de modo a citar os símbolos oficiais da natureza do Tocantins: o girassol, a fava-de-bolota, a arara-canindé, a rolinha-fogo-apagou e a granada.

No caso desses símbolos, trata-se da apropriação, da valorização, da significação e da ressignificação de elementos da natureza que se imprimem, como signos, no imaginário social, por força de 
lei. Na perspectiva de Almeida (2003, p. 72), esse processo "[...] configura-se como uma reinvenção [...]" que "[...] acontece pela (re)significação das coisas naturais e pela reafirmação destas como partes e produtos da sociedade", especialmente quando se utiliza das narrativas históricas para construir a invenção discursiva.

Desse modo, esses símbolos oficiais transformaram-se em veículos de significação, diretamente associados à figura do ex-governador Siqueira Campos, que, nos seus governos, procurou difundir valores cívicos e imprimir um contexto identitário no Tocantins. O ex-governador, de modo a reforçar o caráter simbólico, evoca para si a autoria de todos os símbolos oficiais do estado e da natureza do estado (Siqueira Campos, 2014), tendo em vista os esforços para criar, legitimar e atribuir significado a esses símbolos, que foram compartilhados e introjetados no imaginário social tocantinense como pertencentes à coletividade.

\section{A invenção do girassol como símbolo da natureza do Tocantins}

Dos símbolos criados e propagados pelo poder público, sobretudo nos governos de Siqueira Campos, destaca-se, pela incoerência, o girassol. ${ }^{4}$ Embora não seja planta nativa dos cerrados e das florestas tocantinenses, ${ }^{5}$ o girassol é reconhecido, oficialmente, como símbolo da natureza do Estado do Tocantins e vem sendo assimilado dessa maneira na esfera social, que, de modo geral, cultiva símbolos que lhe são transmitidos.

No contexto de forjadura do símbolo, o poder público e os grupos sociais dominantes justificam a invenção de novos símbolos com explicações que tendem a construir maneiras novas de compreensão histórica, sobretudo no imaginário da população, visando propagar a memória simbólica. Como expressam Hobsbawn e Ranger (2008, p. 8), tais práticas de invenção simbólica têm por objetivo "[...] inculcar certos valores e normas de comportamento através da repetição, o que implica, automaticamente, uma continuidade em relação ao passado histórico apropriado."

No caso do girassol, observa-se uma incorporação, como símbolo da natureza do Tocantins, associada ao ex-governador Siqueira Campos. Nos anos posteriores à criação do estado e de Palmas, ele construiu as justificativas dessa referência simbólica. Tais justificativas perpassam pelo estabelecimento de novas conexões na compreensão de um passado relevante, sobretudo relacionado a Joaquim Teotônio Segurado, desembargador, ouvidor e deputado da Coroa Portuguesa, a quem se atribui a difusão de ideias de autonomia da região norte da Província de Goiás no século XIX. Pela vinculação a esses dados do passado, o ex-governador idealiza uma relação identitária e histórica - Teotônio Segurado, Portugal, autonomia, girassol, por intermédio da alusão aos campos de girassóis existentes em Portugal (Siqueira Campos, 2014).

A luta emancipatória recente, marcada pela ação de Siqueira Campos, alicerçou-se nas ideias separatistas de Teotônio Segurado, bem como nas perspectivas de desenvolvimento social, político e econômico para a região do antigo norte de Goiás. Daí o estabelecimento de novas amarrações simbólicas que enredam o girassol como sinônimo de prosperidade (Siqueira Campos, 2014).

\footnotetext{
${ }^{4} \mathrm{O}$ girassol (Helianthusannus) pertence à família Asteraceaee ordem Asterales (Joly, 2002).

${ }^{5}$ Pesquisas bibliográficas apontam que se trata de uma planta “[...] originária da América do Norte, mas pode ser encontrada no estado selvagem desde as planícies do noroeste do Canadá até a América do Sul” (Nunes et al., 2013, p.151).
} 
Ademais, o ex-governador alega ter recebido uma rocha com imagem de girassol incrustada, encontrada num córrego da Serra do Cachorro de Cócara, no Município de Goiatins (Figura 1). Para o ex-governador, trata-se de um exemplar de fóssil de girassol, que demonstra a presença da flor na região em períodos muito anteriores à criação do estado (Siqueira Campos, 2014).

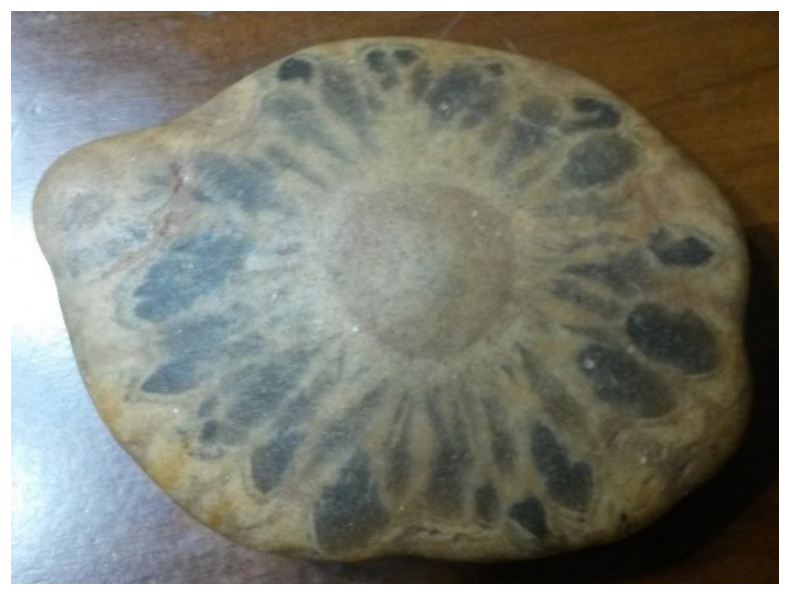

FIGURA 1 - Imagem em rocha supostamente encontrada em córrego no Tocantins (Brasil).

FOTO: Walena Magalhães, 8 nov. 2014.

A forjadura dos símbolos resulta de acontecimentos corriqueiros, destacados por aqueles que edificam os significados. No caso das explicações acerca do girassol no Tocantins, nota-se a necessidade de incentivar e alicerçar tradições associadas aos acontecimentos ocorridos no chão dos ancestrais, de modo a exacerbar um fervor simbólico cultivado por um ou outro acontecimento e pelos esforços emocionais.

Ressalta-se que, no caso dos símbolos forjados, por esforços de quem os edificam e os propagam, as dimensões reais de conhecimento intelectual e científico, como se sabe, perdem-se em prol das dimensões sentimentais de identificação e de reconhecimento, elaborando histórias imaginárias. Trata-se do processo de "[...] reconstrução dos dados fornecidos pelo presente da vida social e projetados sobre um passado reinventado [...]" (Halbwachs, 2006, p. 13).

\subsection{O girassol no cenário político}

As legislações estaduais referentes ao girassol foram instituídas por atos de Siqueira Campos, nas quatro vezes em que foi governador do Tocantins (1989 a 1991; 1995 a 1998; 1999 a 2002; 2011 a 2014), e sua veiculação deu-se por diversas estratégias, notadamente sob auspícios do próprio ex-governador, além de Eduardo Siqueira Campos, seu filho, enquanto prefeito de Palmas (1993 a 1997).

Durante o primeiro mandato de Siqueira Campos (1989 a 1991), o girassol foi cultivado ao lado do atual Museu do Palacinho - primeira sede do governo estadual, em instalação provisória de madeira. Os registros desses primeiros cultivos datam do ano de 1990 (Tocantins, 1990). Com a instalação definitiva do governo estadual no Palácio Araguaia, no platô oval entre as duas principais avenidas da cidade - Teotônio Segurado e Juscelino Kubistchek, observou-se também o plantio de um jardim de girassóis, o que, segundo Fernandes (2011), passou a sugestionar, no imaginário da população, o nome da futura praça cívica - Praça dos Girassóis, ampliando, inclusive, seu potencial simbólico.

Ainda no primeiro mandato, deu-se também a criação do Programa Pioneiros Mirins, em 1989, que usava a imagem do girassol no uniforme das crianças e dos adolescentes, que o carregavam como adorno nos desfiles cívicos na capital (Programa Pioneiros Mirins, 2008). Esse Programa, desativado em 1991, foi retomado no segundo mandato de Siqueira Campos (1995-1998) e regulamentado 
por meio da Lei n. 856, de 26 de julho de 1996 (Tocantins, 1996). Atualmente, o Programa está vinculado à Secretaria do Trabalho e Desenvolvimento Social do Estado e à Política Pública Nacional de Assistência Social, porém, sua imagem permanece diretamente associada à flor girassol (Figura 2) (Programa Pioneiros Mirins, 2008).

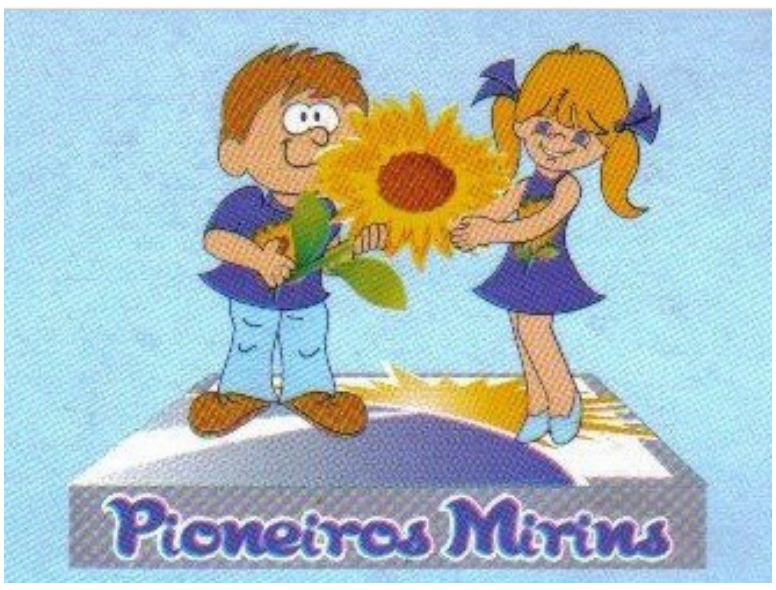

FIGURA 2 - Imagem do Programa Pioneiros Mirins, da Secretaria do Trabalho e Desenvolvimento Social do Estado do Tocantins. FONTE: Programa Pioneiros Mirins (2008).

Quando da posse de Eduardo Siqueira Campos como prefeito de Palmas em 1993, iniciou-se
"[...] uma exaltação sobre o símbolo do girassol, plantando esta flor em alguns pontos estratégicos da cidade. Os espaços foram invadidos pela flor, não mais o verde compunha o cenário da paisagem, mais o amarelo dominava" (Brito, 2010, p. 103). Essa exaltação ao girassol perpetuou-se durante todo o mandato (1993 a 1997).

Entre os anos de 1998 a 2000, no acervo do Jornal do Tocantins, a figura do girassol apareceu nos selos comemorativos do $10^{\circ}, 11^{\circ}$ e $12^{\circ}$ aniversários de criação do estado (Figura 3) (Tocantins..., 1998; Especial..., 1999, 12 Anos, 2000). Ainda no acervo do Jornal do Tocantins, observou-se o uso da imagem do girassol na comunicação social do estado (capas de vídeos, revistas e outros) (O Futuro..., 1998; O Tocantins..., 2001), bem como em painel na parede posterior do gabinete oficial do governador.

Em 7 de setembro de 2000, foi inaugurada a principal praça da capital, centro do poder público estadual, batizada pelo então governador Siqueira Campos de Praça dos Girassóis (Praça..., 2000). Nela, localizam-se a sede do governo estadual - o Palácio Araguaia, assim como a Assembleia Legislativa, o Tribunal de Justiça e as secretarias estaduais. Também estão situados nessa praça diversos monumentos que aludem à criação do estado.
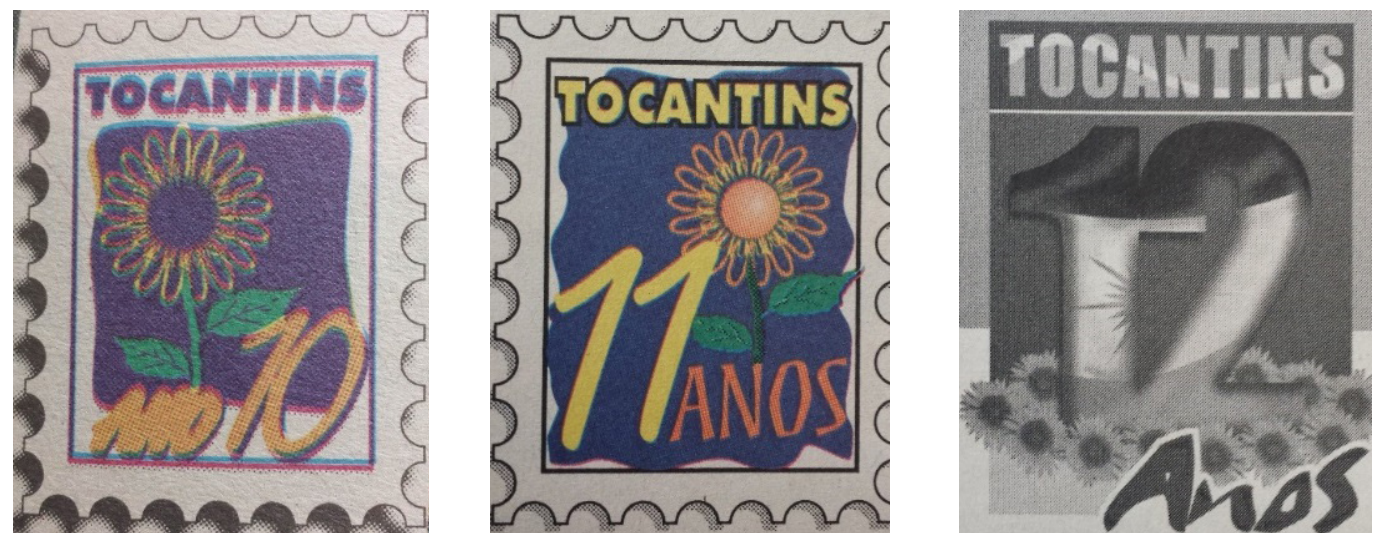

FIGURA 3 - Selos comemorativos dos $10^{\circ}, 11^{\circ}$ e $12^{\circ}$ aniversários de criação do Estado do Tocantins, 1998,1999 e 2000. FONTE: Tocantins..., 1998; Especial..., 1999; 12 Anos (2000). 


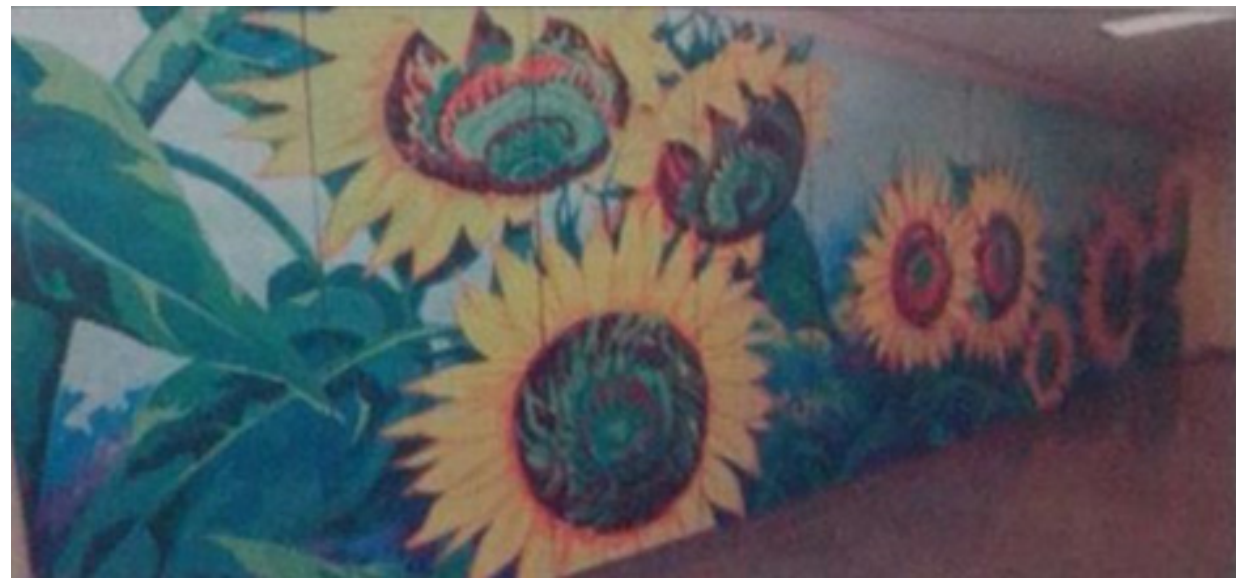

FIGURA 4 - Painel de girassóis da Assembleia Legislativa do Estado do Tocantins, 2010. FONTE: Patrimônios... (2010).

Vale salientar que, no hall de entrada do prédio da Assembleia Legislativa do Tocantins, figurava, até 2005, um painel com mosaicos de girassóis. Esse painel foi retirado em 2006 e, atualmente, encontra-se em uma das salas do segundo piso do referido prédio (Figura 4) (Patrimônios..., 2010).
Durante o restante desse mandato e no último mandato de Siqueira Campos como governador (2011 a 2014), foram semeadas plantações de girassol na Praça dos Girassóis (Figuras 5 e 6). Estratégia bem-sucedida de veiculação do símbolo, pois, tradicionalmente, as camadas sociais cultivam

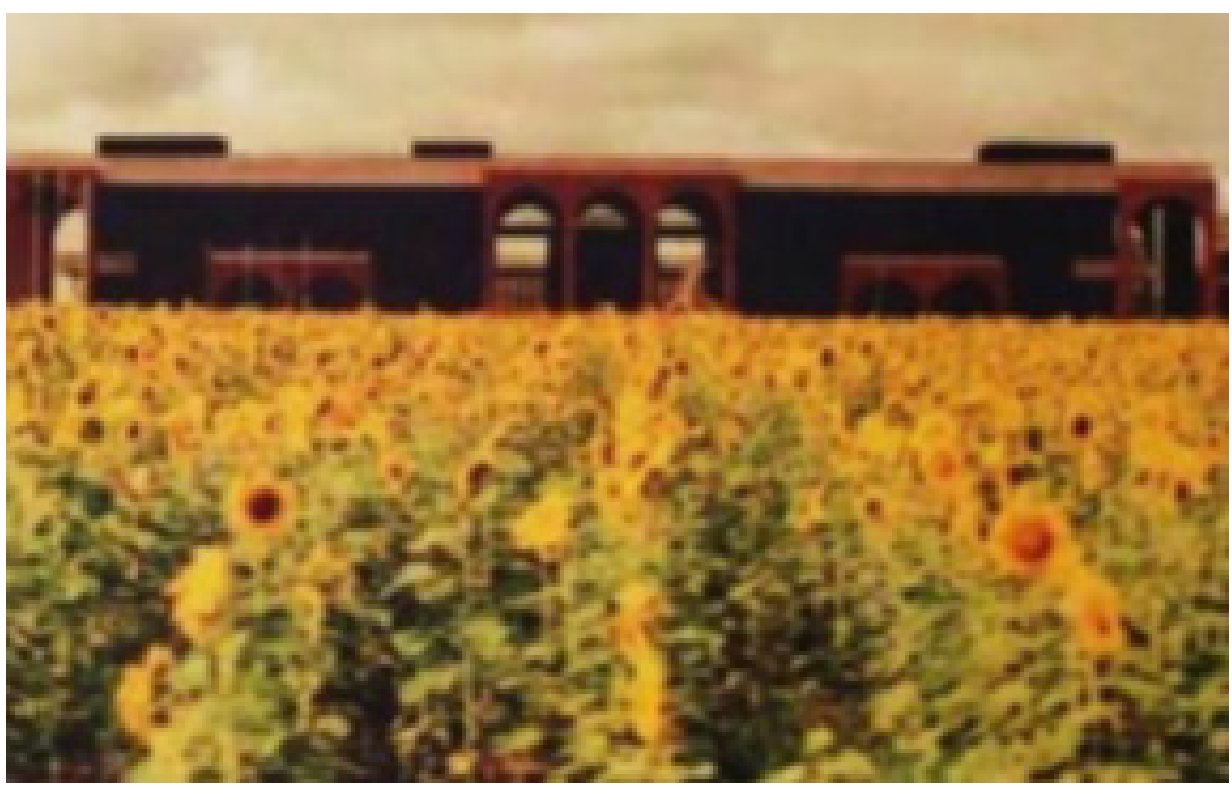

FIGURA 5 - Jardim de girassóis cultivado diante do Palácio Araguaia, na Praça de Girassóis, em Palmas-TO, 2006. FONTE: Fernandes (2011, p. 207). 


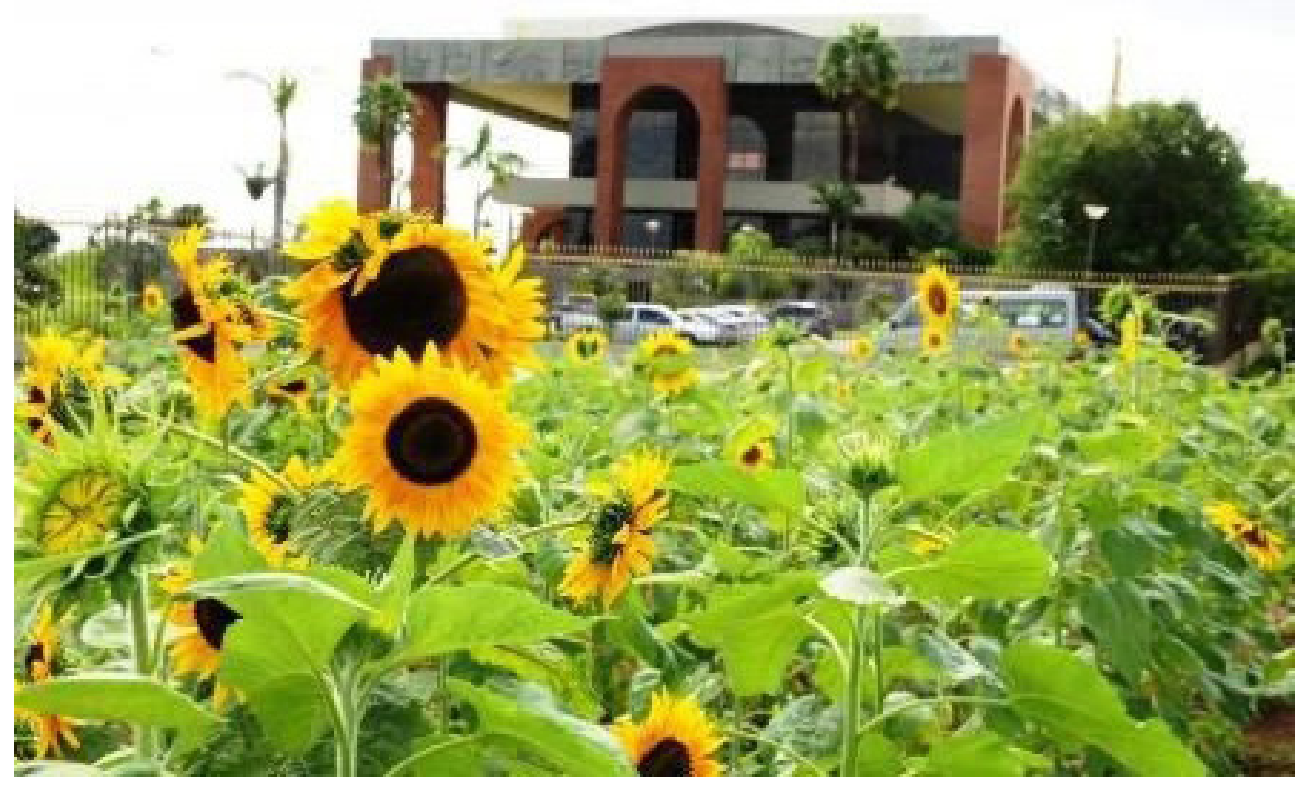

FIGURA 6 - Jardim de girassóis cultivado junto ao Palácio Araguaia, na Praça de Girassóis, em Palmas-TO, 2012. FONTE: Andreucci (2012, s/p.).

símbolos que lhe são transmitidos, mas elegem e propagam, na memória, lugares simbólicos, como a Praça dos Girassóis, que passou a ter um significado referencial.

Posteriormente, criou-se a insígnia Girassóis do Tocantins, por meio do Decreto n. 4460, de 14 de dezembro de 2011, representando mais uma forma de veiculação do símbolo. Trata-se de um broche com forma de girassol, "em ouro, cravejada, ao centro, com uma pedra de esmeralda" (Tocantins, 2011, s/p.). A concessão dessa insígnia é feita, exclusivamente, pelo governador do estado, para conferir distinção a autoridades, pessoas e instituições que tenham prestado relevantes serviços.

Recentemente, Siqueira Campos instituiu, por força da Lei n. 2.810, de 26 de dezembro de 2013 (Tocantins, 2013b), o nome girassol em todas as escolas estaduais de tempo integral, ao todo, 49 escolas, sendo sete em Palmas (Projeto..., 2013).
Segundo o ortal de notícias da Rede Globo, a votação da referida lei causou controvérsias na Assembleia Legislativa, sendo aprovada por votação polêmica de dez votos a favor e nove votos contrários (Aprovado..., 2013). Tal fato expressa que os símbolos podem manifestar-se tanto como meio de afirmação como de contestação. Os parlamentares avessos à proposta acusavam o uso da lei para promoção pessoal do então governador, tendo em vista que o girassol é marca de suas campanhas eleitorais. Notoriamente, os símbolos exibem forte potencial para representar valores e crenças que são transmitidos como se fossem de todos, como se fossem coletivos.

Em visita à residência do ex-governador, para entrevista, e ao Instituto Siqueira Campos, para levantamento documental, foi possível notar a relação extrema do ex-governador com o girassol, observado em placas comemorativas, quadros recebidos de presente, pinturas e tapeçarias, afrescos em 
paredes inteiras, painéis, arranjos de flores e toalhas de mesa, fortalecendo o significado do símbolo e de seu criador.

A veiculação e a propagação constante dos símbolos forjados, por parte do poder público e dos grupos dominantes, revestem esses símbolos de significado e codificam aquilo que deles se pretende, ou seja, a criação de novas referências e de novas identidades para a cidade e para o estado. Na realidade, são estratégias fundamentais para a perpetuação da memória simbólica, sobretudo no âmbito dos símbolos forjados, posto que a “[...] memória é um fenômeno construído” (Pollak, 1992, p. 203).

\subsection{Apropriação do símbolo girassol por instituições e empresas privadas em Palmas-TO}

A veiculação do símbolo girassol foi realizada por meio de um amplo trabalho de divulgação durante os governos de Siqueira Campos, auxiliado pela Secretaria de Comunicação do Estado do Tocantins (SECOM) e respaldado por instituições de comunicação, como jornais impressos, panfletos, rádios e emissoras de televisão.

No bojo desse processo, ou seja, do marketing político-identitário, mesmo os símbolos forjados adquirem significados, que afloram do contato direto. Esses significados são tecidos e transmitidos por pessoas e por diversos canais de expressão, garantindo a permanência e o envolvimento que conduzem à posse e à afeição, denotando ainda identificação e assimilação.

Trata-se de uma representação dominante, passível de identificação tanto na paisagem como em todos os demais objetos e estabelecimentos nos quais sua imagem se faz presente. De fato, os símbolos impostos e, posteriormente, assimilados tornam-se símbolos eternizados na memória e, dessa maneira, o girassol foi apropriado como referência não só em instituições públicas, mas também em instituições e empresas privadas na capital, as quais, rapidamente, absorveram e adotaram a imagem do girassol como símbolo da cidade e do Tocantins.

Em Palmas, foram levantadas, no total, 22 instituições e empresas privadas que estão associadas ao símbolo girassol, por meio de pesquisas realizadas em catálogo telefônico, sítios de busca da rede mundial de computadores (Internet), na Junta Comercial do Estado do Tocantins (JUCETINS) e na Delegacia da Receita Federal. ${ }^{6}$ Essas instituições e empresas, inclusive, têm o termo girassol no nome fantasia de seus estabelecimentos.

Nota-se que a imagem do girassol, associada ou não ao seu criador, o ex-governador Siqueira Campos, foi apropriada por essas instituições e empresas, reforçando-a como símbolo do estado e da capital para a população. O movimento de apropriação pelas instituições e empresas privadas acaba por ratificar a assimilação do símbolo forjado no inconsciente coletivo da população, ressignificando a representação inventada.

\section{Considerações finais}

A partir da análise documental, identificou-se que o girassol, no Estado do Tocantins e em Palmas, foi forjado como símbolo e impregnado de intenções, sobretudo na tentativa de tornar-se parte do estado e de sua capital, de modo a perpetuar-se na subjetividade do ser tocantinense e do ser palmense, a partir dos referenciais impostos pelo poder

${ }^{6}$ A JUCETINS e a Receita Federal não se dispuseram a fornecer informações, justificando motivos de sigilo fiscal. 
instaurado, mormente na figura do ex-governador Siqueira Campos, expressando uma relação de identidade e poder.

Essa relação - identidade e poder - parece ser a relação-chave em torno da forjadura dos símbolos e das representações simbólicas que foram produzidos após a criação do novo estado e de sua capital, especialmente no que diz respeito ao girassol como símbolo legitimamente tocantinense. Em geral, os símbolos são forjados para expressar e ratificar valores identitários e exibir poder, criando e alterando padrões de significados, no intuito de modelar o imaginário social e, assim, garantir a perpetuação do poder.

O conjunto de símbolos produzido no Tocantins, a exemplo dos símbolos oficiais e da natureza do estado, objetiva o fortalecimento das identidades territoriais - diante do suposto "vazio" identitário (Rodrigues, 2011) - e a construção de uma memória para o futuro no imaginário social (Silva, 2008), capaz de exibir e garantir a perpetuação dos grupos políticos associados ao próprio processo de criação do estado. Trata-se da forjadura de símbolos para a tradição, para o devir, sobretudo pelos esforços de projeção de memória de um passado recente.

\section{Referências}

12 anos. Jornal do Tocantins, Palmas, 05 out. 2000. Caderno B Especial.

Almeida, M. G. Cultura ecológica e biodiversidade. Mercator, 2(3), 71-82, 2003.

Andreucci, L. Praça dos Girassóis- Apontador. 26 fev. 2012. Disponível em: $<$ http://www.apontador.com.br/local/ to/palmas/parques/C4078799094B0Z4B0B/praca_dos_girassois.html\#photo_tab >. Acesso em: 20 nov. 2014.

Aprovado projeto que inclui girassol nos nomes de escolas estaduais. G1 Tocantins, Palmas, 26 dez. 2013. Disponível em: <http://g1.globo.com/to/tocantins/noticia/2013/12/
Esses símbolos do Tocantins, especialmente os de sentido político e os que atribuem significados à natureza e às construções humanas passadas e presentes, foram implantados pelo poder público de forma emblemática, tendo, inclusive, seus significados contestados. Diante da forjadura, da pluralidade de significados, das intenções dos criadores e das interpretações populares, esses símbolos tornam-se uma prática ou uma tradição inventada, pois são invenções "[...] gerais e vagas quanto à natureza dos valores, direitos e obrigações que procuravam inculcar nos membros de um determinado grupo" (Hobsbawn \& Ranger, 2008, p. 19).

Apesar dos significados arquitetados, das situações imprecisas - como no caso do girassol - e das contestações políticas e socioculturais, tais símbolos, veiculados pelo próprio poder público e pelas elites políticas, são, gradativamente, assimilados e apropriados pela sociedade. Essa apropriação deu-se de várias formas: um dos exemplos é o uso do nome e da imagem do girassol em diversos estabelecimentos privados, posto que os símbolos são poderosos meios de comunicação.

aprovado-projeto-que-inclui-girassol-nos-nomes-de-escolas-estaduais.html>. Acesso em: 20 out. 2014.

Boyer, M. C. The city of collective memory: its historical imagery and architectural entertainments. Cambridge: MIT Press, 1994.

Brasil. Constituição (1988). Constituição da República Federativa do Brasil. Brasília, out. 1988. Disponível em: $<$ http://www.planalto.gov.br/ccivil_03/constituicao/constituicao. htm>.

Brito, E. P. Do sol que gira (o tempo) aos girassóis (o espaço). Entre-Lugar, 1(1), 99-112, 2010. 
Corrêa, R. L. Monumentos, política e espaço. In: Rosendahl, Z.; Corrêa, R. L. Geografia Cultural: uma antologia (volume II). Rio de Janeiro: Eduerj, 2013. p. 73-89.

Costa dos Anjos, A. C. Do girassol ao capim dourado: a apropriação de elementos da natureza na construção de símbolos político-identitários no estado do Tocantins. 2015. 326 f. Palmas, Dissertação (Mestrado em Ciências Ambientais) - Universidade Federal do Tocantins, 2015.

Especial 11 anos. Jornal do Tocantins, Palmas, 5 out. 1999. Caderno B Especial.

Fernandes, L. D. As praças cívicas das novas capitais brasileiras. 2011. 293 f. Dissertação (Mestrado em Arquitetura e Urbanismo) - Universidade de Brasília, Brasília, 2011.

Halbwachs, M. A memória coletiva. São Paulo: Centauro, 2006.

Hobsbawn, E.; Ranger, T. A invenção das tradições. 6. ed. Rio de Janeiro: Paz e Terra, 2008.

Joly, A. B. Botânica: introdução à taxonomia vegetal. 13. ed. São Paulo: Companhia Editora Nacional, 2002.

Nunes, T. B.; Pilon, A.; Fluminhan, A. Avaliação do desempenho agronômico de genótipos de girassol (Helianthus annus L.) cultivados na região oeste paulista e análise do rendimento de óleo matéria seca e proteína bruta. Fórum Ambiental da Alta Paulista, 9(1), 150-165, 2013. Disponível em: <http://amigosdanatureza.org.br/publicacoes/index. php/forum_ambiental/article/view/602>.

O Futuro é aqui. Jornal do Tocantins, Palmas, 25 jan. 1998. Editorial Governo do Tocantins Ano 3.

O Tocantins em 13 atos. Jornal do Tocantins, Palmas, 5 out. 2001. Caderno B Especial.

Oliveira, J. M. M. de. Estratégias separatistas e ordenamento territorial: a criação de Palmas na consolidação do estado do Tocantins. 297 f. Uberlândia, Tese (Doutorado em Geografia) - Universidade Federal de Uberlândia, 2012.

Patrimônios tocantinenses esquecidos com o tempo. Jornal do Tocantins, Palmas, 26 jan. 2010. Pauta do Leitor.

Pollak, M. Memória e identidade social. Revista Estudos Históricos, 5(10), 200-212, 1992.

Praça dos Girassóis, a nossa praça. Almanaque Cultural do Tocantins, 2(10), 1-13, 2000.
Programa Pioneiros Mirins. História do Programa Mirins. [S.l.: s.n.], 2008. Disponível em: $<$ http://pioneirosmirins. blogspot.com.br/>. Acesso em: 07 jan.2015.

Projeto do governo diz que todas as escolas devem se chamar girassol. G1 Tocantins, Palmas, 25 out. 2013. Disponível em: <http://g1.globo.com/to/tocantins/noticia/2013/10/ escolas-estaduais-podem-ganhar-nome-de-flor-que-e-simbolo-do.html>. Acesso em: 20 out. 2014.

Rodrigues, J. C. Espaço, política e identidade cultural no estado do Tocantins, Brasil: pensamento e imaginação geográfica. In: Actas do 12. ${ }^{\circ}$ Colóquio Ibérico de Geografia, Porto: Universidade do Porto, 2010.

Rodrigues, J. C.Experiência, identidade e a criação do Tocantins. Revista Formação Online, 1(18), 24-38, 2011.

Silva, V. C. P. "Girassóis de pedra”: imagens e metáforas de uma cidade em busca do tempo. 2008. 239 f. Presidente Prudente, Tese (Doutorado em Geografia) - Universidade Estadual Paulista, 2008.

Siqueira Campos, José Wilson: entrevista. [7 nov. 2014] Entrevistadores: Liliane Guimarães, Walena Magalhães. Palmas: arquivo pessoal digital. Mp4 (26.51 minutos).

Sola-Morales, S. Hacia una epistemologíadel concepto de símbolo. Cinta Moebio, 49, 2014.

Tocantins (Estado). Constituição do Estado do Tocantins, 1989a. Palmas: Assembleia Legislativa, 2012. Disponível em: <http://www2.senado.leg.br/bdsf/item/id/70431>.

Tocantins (Estado). Lei n. 92, de 17 de novembro de 1989. Cria o brasão de armas do Estado do Tocantins. Palmas, 17 nov. 1989b. Disponível em: <http://www.al.to.gov.br/ legislacao Estadual $>$.

Tocantins (Estado). Lei n. 94, de 17 de novembro de 1989. Institui a bandeira do Estado do Tocantins. Palmas, 17 nov. 1989c. Disponível em: <http://www.al.to.gov.br/legislacaoEstadual $>$.

Tocantins (Estado). Secretaria de Comunicação do Estado do Tocantins (SECOM). Palmas 1990 - Primeiro Girassol. 1990. Altura: 3543 pixels. Largura: 2790 pixels. 300 dpi.24 BIT sRGB. 8,54 Mb. Formato JPEG.

Tocantins (Estado). Lei n. 856, de 26 de julho de 1996. Institui a Bolsa de Complementaridade Escolar, destinada aos Pioneiros Mirins, e dá outras providências. Palmas, 
26 jul. 1996. Disponível em: <http://www.al.to.gov.br/ legislacaoEstadual $>$.

Tocantins (Estado). Lei n. 915, de 16 de julho de 1997. Define, como símbolos da natureza do Estado, a flor, a árvore, o pássaro e a pedra que especifica. Palmas, 16 jul. 1997. Disponível em: <http://www.al.to.gov.br/legislacaoEstadual $>$.

Tocantins (Estado). Lei n. 977, de 30 de abril de 1998. Adota o hino oficial do Estado e dá outras providências. Palmas, 30 abr. 1998. Disponível em: <http://www.al.to. gov.br/legislacao Estadual $>$.

Tocantins (Estado). Lei n. 1.367, de 31 de dezembro de 2002. Adota o canto "Hino ao Tocantins" como canção-símbolo do estado do Tocantins. Palmas, 31 dez. 2002. Disponível em: $<$ http://www.al.to.gov.br/legislacaoEstadual $>$.

Tocantins (Estado). Decreto n. 4.460, de 14 de dezembro de 2011. Cria a insígnia Girassóis do Tocantins, e adota outras providências. Palmas, 14 dez. 2011. Disponível em: <http:// diariooficial.to.gov.br/download/1873/>.

Tocantins (Estado). Lei n. 2.619, de 9 de agosto de 2012. Define os símbolos da natureza do estado do Tocantins e adota outras providências. Palmas, 9 ago. 2012. Disponível em: <http://www.al.to.gov.br/legislacaoEstadual $>$.

Tocantins (Estado). Ato n. 1.063, de 6 de junho de 2013a. Disponível em: <http://www.jusbrasil.com.br/diarios/55243856/doeto-06-06-2013-pg-4>.

Tocantins (Estado). Lei n. 2.810, de 26 de dezembro de 2013. Atribui nova denominação às unidades escolaresespecificadas. Palmas, 26 dez. 2013b. Disponível em: <http://www. al.to.gov.br/legislacaoestadual $>$.

Tocantins 10 anos. Jornal do Tocantins, Palmas, 5 out. 1998. Arte \& Vida 2. 